\section{Blood Pressure Measurement in Morbid Obesity: Comparison between Forearm and Intra-Arterial Assessment of Blood Pressure}

\section{Croteau Sara, Caroline Vallière, Julie Martin, Jean} Bussières, Jean-Roch Boudreault, Simon Biron, Simon Marceau, Frederic-Simon Hould, Stefane Lebel and Paul Poirier, Institut universitaire de Cardiologie et de pneumologie, Hôpital Laval, Québec, Canada

Background: Obesity is associated with high blood pressure. Measurement of blood pressure (BP) in morbid obesity with a larger cuff bladder may be erroneous due to the anatomy of their upper limb and/or a nonsuitable cuff bladder. The objective of the study was to compare a non-invasive technique of BP measurement on the forearm with an appropriate standard blood cuff bladder to an invasive method (intraarterial measurement in the radial artery) in two groups of subjects; non obese (NO) and morbidly obese (MO).

Methods: Twenty-seven NO subjects with a mean body mass index (BMI) of 25,6 $\pm 2,7 \mathrm{~kg} / \mathrm{m}^{2}$ were evaluated using two different techniques for blood pressure measurement. Measures were performed, in a supine position, at the forearm level with a standard cuff bladder (Welch Allyn, NY, USA) and on the opposite forearm using an intra-arterial access. The NO group was compared to $20 \mathrm{MO}$ subjects with a mean BMI of $5,1 \pm 8,7 \mathrm{~kg} / \mathrm{m}^{2}$. The MO group was evaluated during a bariatric surgery procedure, with regular intervals (10 to $15 \mathrm{~min}$ ) using the same two methods described above.

Results: A difference was observed between the two techniques of blood pressure measurements $(P<0.05$ and $P<0.01$ intra-arterial vs. cuff bladder for the NO and the MO groups respectively) (see Table). Correlations between the two techniques were observed in the NO group $(P<0.001)$ for the systolic BP $(r=0,823)$ and the diastolic BP $(r=0,769)$. Similar correlations were also observed in the MO group for the systolic BP $(\mathrm{r}=0,792, P<0,001)$ and the diastolic BP $(\mathrm{r}=0,830$, $P<0,001$; Table).

\begin{tabular}{|c|c|c|c|c|}
\hline & $\begin{array}{c}\text { SBP cuff } \\
\text { bladder }\end{array}$ & $\begin{array}{c}\text { SBP intra- } \\
\text { arterial }\end{array}$ & $\begin{array}{c}\text { SBP cuff } \\
\text { bladder }\end{array}$ & $\begin{array}{c}\text { SBP intra- } \\
\text { arterial }\end{array}$ \\
\hline NO & $156 \pm 23$ & $144 \pm 19$ & $85 \pm 9$ & $62 \pm 9$ \\
group & $\mathrm{mmHg}$ & $\mathrm{mmHg}$ & $\mathrm{mmHg}$ & $\mathrm{mmHg}$ \\
\hline MO & $136 \pm 26$ & $127 \pm 26$ & $65 \pm 17$ & $68 \pm 14$ \\
group & $\mathrm{mmHg}$ & $\mathrm{mmHg}$ & $\mathrm{mmHg}$ & $\mathrm{mmHg}$ \\
\hline
\end{tabular}

Conclusion: Although different, BP measurements at the forearm level in MO subjects seems to be clinically valid. This technique may be used in this specific population as an alternative for the measurement of BP.

\section{The Infrequency of Spirometry Use in Medical Clinics}

De Dios Jose Angelo A., Luis Diez, Richard ZuWallack, and Bimalin Lahiri, The University of Connecticut School of Medicine, Farmington, CT and St. Francis Hospital and Medical Center, Hartford, CT USA

Background: Spirometry is advocated for adults with obstructive lung disease such as asthma or chronic obstructive lung disease (COPD), for individuals with risk factors such as cigarette smoking, and for patients with chronic respiratory symptoms. This record review study was performed to determine how frequent medical residents order spirometry for the above indications.

Methods: Outpatient general medical clinic records from 337 patients followed in the medical clinics of a large, teaching hospital in an urban setting were reviewed. Inclusion criteria for review included age $\geq$ $45 \mathrm{yr}$ and one of the following: 1) a diagnosis of asthma and/or COPD, 2) either current or previous cigarette smoking, 3) one or more of the following chronic respiratory symptoms: dyspnea, cough, sputum production.

Results: The mean (SD) age was $57 \pm 10$ yr. Of this group, only $31 \%$ had spirometry or an order for spirometry documented in the outpatient record.

Conclusion: This finding underscores the underutilization of spirometry as a diagnostic tool, even in an academic setting. 